\title{
TU/e emonownen

\section{Experimental and numerical investigation of the vortex formation process behind a heated cylinder}

\section{Citation for published version (APA):}

Ren, M., Rindt, C. C. M., \& Steenhoven, van, A. A. (2004). Experimental and numerical investigation of the vortex formation process behind a heated cylinder. Physics of Fluids, 16(8), 3103-3114.

https://doi.org/10.1063/1.1765834

DOI:

10.1063/1.1765834

Document status and date:

Published: 01/01/2004

\section{Document Version:}

Publisher's PDF, also known as Version of Record (includes final page, issue and volume numbers)

\section{Please check the document version of this publication:}

- A submitted manuscript is the version of the article upon submission and before peer-review. There can be important differences between the submitted version and the official published version of record. People interested in the research are advised to contact the author for the final version of the publication, or visit the $\mathrm{DOI}$ to the publisher's website.

- The final author version and the galley proof are versions of the publication after peer review.

- The final published version features the final layout of the paper including the volume, issue and page numbers.

Link to publication

\section{General rights}

Copyright and moral rights for the publications made accessible in the public portal are retained by the authors and/or other copyright owners and it is a condition of accessing publications that users recognise and abide by the legal requirements associated with these rights.

- Users may download and print one copy of any publication from the public portal for the purpose of private study or research.

- You may not further distribute the material or use it for any profit-making activity or commercial gain

- You may freely distribute the URL identifying the publication in the public portal.

If the publication is distributed under the terms of Article 25fa of the Dutch Copyright Act, indicated by the "Taverne" license above, please follow below link for the End User Agreement:

www.tue.nl/taverne

Take down policy

If you believe that this document breaches copyright please contact us at:

openaccess@tue.nl

providing details and we will investigate your claim. 


\title{
Experimental and numerical investigation of the vortex formation process behind a heated cylinder
}

\author{
Maosheng Ren, Camilo C. M. Rindt, and Anton A. van Steenhoven \\ Laboratory for Energy Technology, Department of Mechanical Engineering, \\ Eindhoven University of Technology, P.O. Box 513, 5600 MB Eindhoven, The Netherlands
}

(Received 5 October 2003; accepted 30 April 2004; published online 6 July 2004)

\begin{abstract}
This paper describes the three-dimensional (3D) vortex formation process behind a heated cylinder at low Reynolds numbers. Both experimental and numerical techniques are used, including an electrochemical tin-precipitation visualization method, a two-dimensional (2D) high resolution particle velocimetry technique, and a 3D spectral element method. The wake flow is simultaneously investigated in two perpendicular planes using a "dual-plane" configuration. It appears that for Reynolds number around 100 and Richardson number larger than 1.0 thermal plumes occur in the far wake. Correspondingly distinct counterrotating vortices, with a spanwise wavelength of two cylinder diameters, are shown in the near wake. Furthermore, a difference in the flow motion for "in-plume" and "out-of-plume" positions is observed. The vortex shedding process for the "out-of-plume" positions is quite similar to the one for an unheated cylinder, which is a 2D flow. At in-plume positions, it is observed that the flow moves upward from the lower to the upper half of the wake. From the calculated temperature field, a region of unstable thermal stratification in gravity direction is observed at the in-plume positions. This indicates that the upward motion at the in-plume positions is induced by buoyancy when the temperature gradient is large enough. () 2004 American Institute of Physics. [DOI: 10.1063/1.1765834]
\end{abstract}

\section{INTRODUCTION}

The mechanism of vortex shedding behind bluff bodies has been attracting the attention of both engineers and scientists for a long time. It can even be traced back to the sixteenth century when Leonardo da Vinci made drawings of the surface pattern of the flow past an obstacle. Meanwhile, wake flows behind bluff bodies have direct engineering significance. The formation of vortices behind bluff bodies is important since they determine not only the drag but also the heat transfer to the environment.

Over the last ten years, a lot of attention has been paid to the three-dimensional (3D) vortex dynamics behind a cylinder. Experimental and theoretical studies of 3D wake transition significantly contributed to the understanding of the dynamics. ${ }^{1,2}$ From a fundamental point of view, studies on the instability mechanisms resulting in the formation of twodimensional (2D) and 3D vortical structures can contribute to better understanding of laminar-turbulent transition and may lead to ways to actively control the features of the flow.

Based on velocity measurements, Roshko ${ }^{3}$ described the wake transition and flow regimes. A visualization of $\mathrm{Hama}^{4}$ showed that the instability in the wake transition takes the form of a three-dimensional waviness of the von Kármán vortices. This is essentially what Gerrard ${ }^{5}$ later called "fingers of dye." Williamson's flow visualization ${ }^{6}$ showed that Gerrard's dye fingers are associated with vortex loops and streamwise vortices. Furthermore, he observed two discontinuous changes in a Strouhal-Reynolds number relationship. The first discontinuity takes places at a Reynolds number around 180-190 and the second discontinuity occurs at a
Reynolds number around 230-260. Williamson ${ }^{6}$ suggested that the two discontinuities in the Strouhal-Reynolds diagram correspond to two different modes, mode- $A$ and mode$B$ instabilities. The two different modes scale on different physical features of the flow: mode- $A$ instability has a spanwise wavelength of 3-4 cylinder diameters and mode- $B$ instability has a spanwise wavelength of 1 cylinder diameter.

The effect of heat input on the cylinder wake flow has received relatively little attention, although mixed convection around bluff bodies is of great importance for engineering applications. For example, in electronics cooling, the flow behind a cooled component strongly influences the cooling behavior of downstream placed components. Noto et $\mathrm{al}^{7}{ }^{7}$ studied the flow around a heated horizontal cylinder exposed to a vertically upward directed flow. They found that by increasing the heat input, the Strouhal number first increases. However, above a critical value of heat input, the Strouhal number becomes zero and vortex shedding is suppressed. A further increase of the heat input causes these vortices to disappear, ending up with a thermal plume. Furthermore, Noto ${ }^{8}$ found that the angle of attack (between the main flow direction and the gravitational vector) has a significant influence on the wake flow features.

When the cylinder is exposed to a horizontal cross flow, Lecordier et al. ${ }^{9}$ and Wang et al. ${ }^{10}$ observed that for a Reynolds number just above the critical value of $\operatorname{Re}_{c}=49$ the vortex shedding could be suppressed by a small amount of heat input to the cylinder in air. Heating the wake flow has an opposite effect in air and water, due to the difference in the thermal dependence of the kinematic viscosity. However, about the effect of heat input on the behavior of coherent 
structures behind the cylinder had not been properly understood until the recent studies by Kieft et al. ${ }^{11,12} \mathrm{He}$ investigated the wake structure behind a heated horizontal cylinder in cross flow with water as the working fluid. For low Reynolds numbers, Kieft et al. ${ }^{11}$ found that by heating the cylinder, the vortices in the upper and lower rows acquire different strengths due to baroclinic vorticity production. This strength difference increases for increasing Richardson numbers. It was observed that for small Richardson numbers the shed vortices move slightly downwards. A more extensive literature review and a summary of earlier results on the wake behavior behind a heated cylinder of our research group were given by van Steenhoven and Rindt. ${ }^{13}$

From a recent study, ${ }^{14}$ it was shown that, when the cylinder is heated, a 3D transition in the wake flow occurs at a lower Reynolds number than for the unheated case. From visualizations for $\mathrm{Re}=117$ and $\mathrm{Ri} \geqslant 1$ thermal plumes occur in the far wake, as shown in Fig. 6(c). It was observed that the thermal plumes escape from the upper vortices. The spanwise distance between the plumes, observed by a topview visualization, is around twice the cylinder diameter. ${ }^{15}$

In the present paper, the $3 \mathrm{D}$ vortex formation process behind a heated cylinder is studied at low Reynolds numbers. Both experimental and numerical techniques are used, including an electrochemical tin-precipitation visualization method, a high resolution particle velocimetry (HPV) technique, and a 3D spectral element method (3D-SEM). The paper is organized as follows. In Sec. II, a description of the problem definition is given, together with the experimental setup and investigation techniques. In Sec. III, the twodimensional vortex formation process is studied by using the flow topology of instantaneous streamlines and visualizations. The observations of 3D transition behind a heated cylinder are presented in Sec. IV. After that, in Sec. V the 3D vortex formation process is studied in two perpendicular planes by using a dual-plane configuration. Furthermore in Sec. VI, calculated velocity and temperature fields are presented. There we show that the flow motion is quite different at "in-plume" and "out-of-plume" positions. Finally, the main conclusions are given.

\section{EXPERIMENTAL SETUP AND TECHNIQUES}

\section{A. Problem definition}

In the current investigation buoyancy induced 3D transition behind a heated cylinder is investigated at low Reynolds numbers. The cylinder is exposed to a horizontal uniform cross flow (Fig. 1, where the $z$ axis is the spanwise direction, the $x$ axis is the streamwise direction, and the cylinder center is positioned at $x=0, y=0$ ).

In the calculations, the flow is assumed to obey the Boussinesq approximation; the density variations are negligible except in the buoyancy force. The dimensionless conservation equations for mass, momentum, and energy are, respectively, the following:

$\boldsymbol{\nabla} \cdot \mathbf{u}=0$

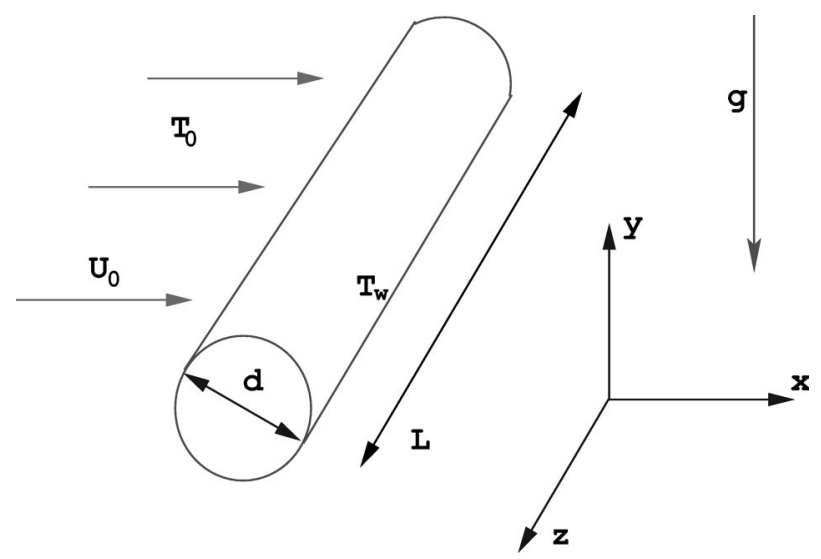

FIG. 1. Problem definition.

$$
\begin{aligned}
& \frac{\partial \mathbf{u}}{\partial t}+\mathbf{u} \cdot \nabla \mathbf{u}=-\nabla p+\frac{1}{\operatorname{Re}} \nabla^{2} \mathbf{u}-\operatorname{Ri} \Theta \mathbf{g}, \\
& \frac{\partial \Theta}{\partial t}+\mathbf{u} \cdot \nabla \Theta=\frac{1}{\operatorname{Re} \operatorname{Pr}} \nabla^{2} \Theta,
\end{aligned}
$$

with $\operatorname{Re}=U_{0} d / \nu$ being the Reynolds number, $\mathrm{Ri}=\mathrm{Gr} / \mathrm{Re}^{2}$ $=g \beta \Delta T d / U_{0}^{2}$ the Richardson number, $\mathrm{Gr}=g \beta \Delta T d^{3} / \nu^{2}$ the Grashof number, $\operatorname{Pr}=\nu / \kappa$ the Prandtl number, $\beta$ the expansion coefficient, $\kappa$ the thermal diffusivity, $g$ the gravity constant, $\mathbf{g}=(0,-1,0)^{T}$ the dimensionless gravity vector, $\Theta$ $=\left(T-T_{0}\right) /\left(T_{w}-T_{0}\right)$ the dimensionless temperature, $\mathbf{u}$ the dimensionless velocity, and $p$ the dimensionless pressure. From these dimensionless conservation equations with suitable boundary conditions, one can conclude that the character of the flow depends on the dimensionless parameters Re, $\mathrm{Ri}$, and $\mathrm{Pr}$. In the current investigation, $\mathrm{Ri}$ is varied between 0 and 1 , while $\mathrm{Re}$ is varied from 85 to 117 . The Prandtl number is approximately around 6 because water is used as the working fluid.

\section{B. Experimental setup}

The apparatus used in the experiment consists of three parts: the water tank, the light source with illumination system, and the image recording with postprocessing system.

The flow was investigated in a so-called towing tank configuration, as shown in Fig. 2, with dimensions length $\times$ width $\times$ height $=500 \times 50 \times 75 \mathrm{~cm}^{3}$. In this configuration the cylinder is towed through the water with a constant velocity $U_{0}$. The cylinder has length $L=495 \mathrm{~mm}$ and diameter $d=8.5 \mathrm{~mm}$ (aspect ratio $L / d=58$ ). The test section consists of $15 \mathrm{~mm}$ thick glass windows, held together by a steel frame, so the towing tank is optically accessible from all directions. The cylinder is positioned between two perspex plates, which are connected to a stiff structure, which also carries the measurement equipment, such as cameras and light sources. The stiff construction can be translated along two rails that are mounted on top of the water tank. The perspex plates are constructed in such a way that minimum disturbances are created and oblique vortex shedding is suppressed. A cylindrical heating element with diameter 6.35 $\mathrm{mm}$ is used to obtain the desired cylinder wall temperature. 


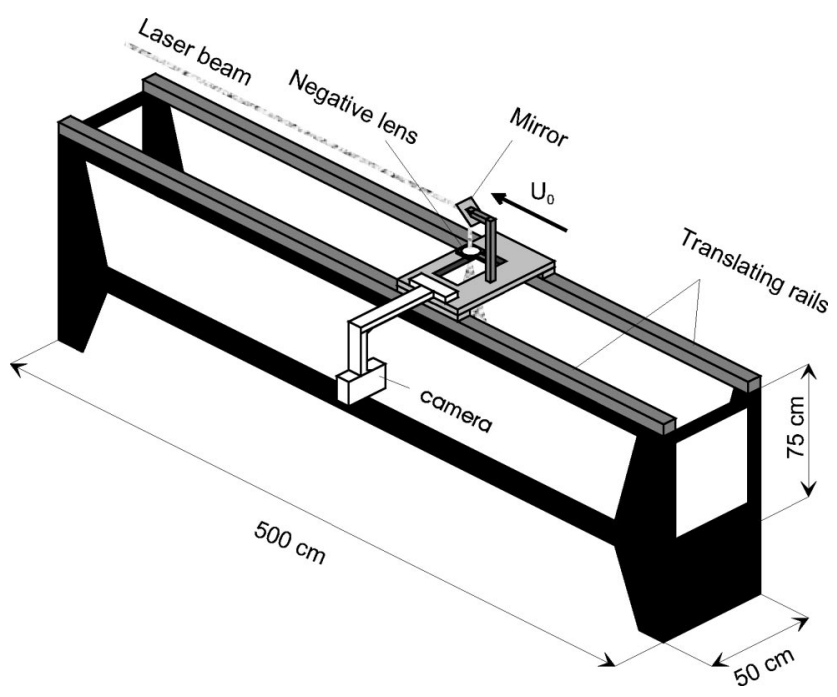

FIG. 2. Experimental setup.

The whole of the tank is supported by a sturdy steel framework and is situated in a temperature-controlled laboratory. A detailed description of the water tank is given in Ref. 16.

For the light source, a pulsed Nd:YAG (YAG-yttrium aluminum garnet) laser is used. The laser emits light with a wavelength of $532 \mathrm{~nm}$. One laser pulse has a duration of $6 \mathrm{~ns}$ and a maximum energy of $200 \mathrm{~mJ}$. The laser beam is directed parallel to the bottom of the water tank, as shown in Fig. 2. The beam passes a negative lens to form a thin laser sheet. The laser is triggered by a camera and operates at $29 \mathrm{~Hz}$.

The recording is performed by a charge-coupled device (CCD) camera (Kodak Megaplus, 10-bit ES1.0, 1008 $\times 1019$ pixels $^{2}$ ). The camera records images at a maximum frame rate of $29 \mathrm{~Hz}$. A Nikon lens with a focal distance of 50 $\mathrm{cm}$ is used in front of the CCD camera. A detailed description of the image recording and postprocessing system is given in Ref. 17.

\section{Dual-plane configuration}

To investigate the mechanism of the (3D) vortex formation process behind a heated cylinder, it is important to know how the measurement plane $(x-y)$ is related to the spanwise vortex distribution. By means of using two laser sheets (Nd:YAG and argon ion) and two cameras, the wake flow could be measured in two perpendicular planes $(x-y$ and $x-z$ ) simultaneously. In Fig. 3, camera CCD1 measures the flow illuminated by the Nd:YAG laser. The mechanism of the vortex formation is studied in the $x-y$ plane from a side view. Camera CCD2 is used to determine the spanwise distribution $(x-z$ plane). The flow field recorded by camera CCD2 is illuminated by an argon-ion laser. From now on, the technique with two lasers and two cameras in two perpendicular planes will be referred to dual-plane configuration. In this configuration, two notch filters are used in front of the cameras to block away reflections from the bottom and sidewalls, as shown in Fig. 3.

An example of flow pattern using the dual-plane configuration is shown in Fig. 4. The flow field is visualized at

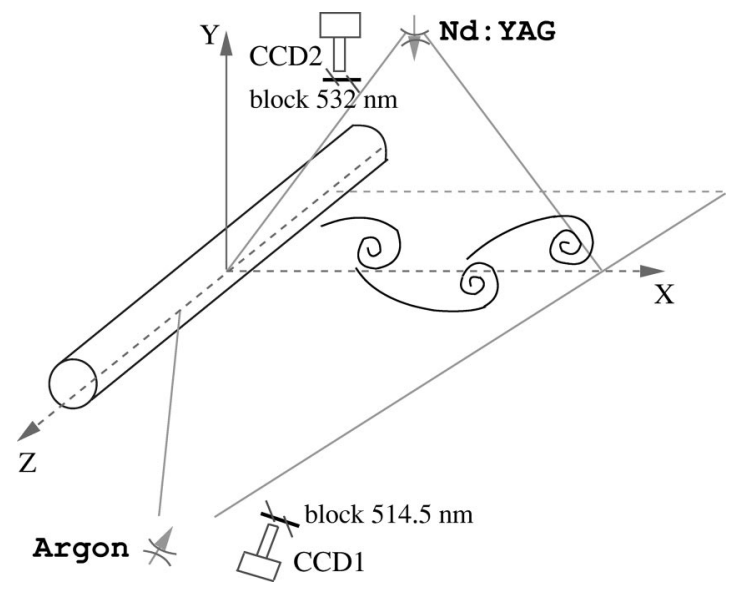

FIG. 3. Configuration of dual-plane measurement.

$\mathrm{Re}=85$ and $\mathrm{Ri}=1.0$ by means of an electrochemical tinprecipitation method.

\section{Investigation techniques}

\section{Visualization method}

Flow visualizations are carried out using an electrochemical tin-precipitation method. In this method tin ions are separated from an anode, by applying a voltage difference. In the current setup a thin tin wire which is used as an anode is positioned upstream of the cylinder. Because the tin ions do

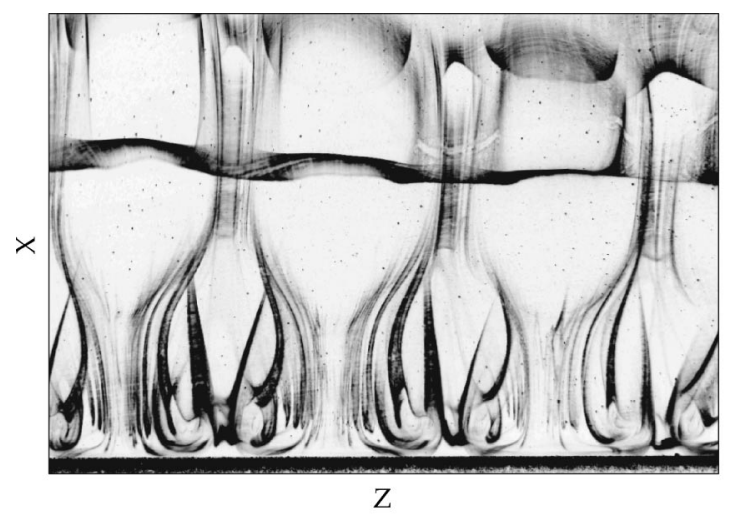

(a) top-view

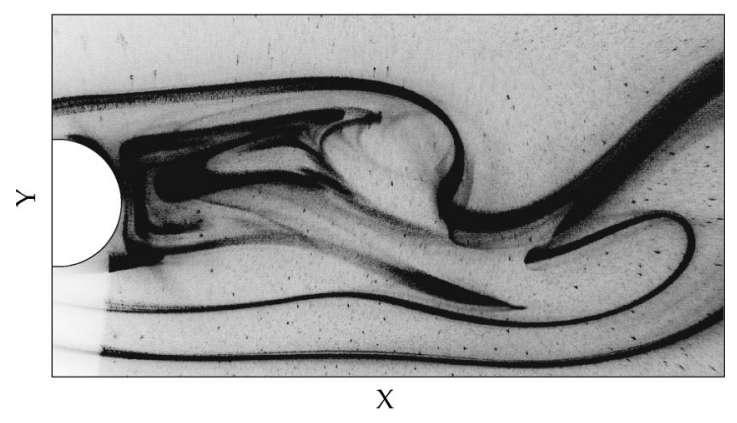

(b) side-view

FIG. 4. The wake pattern recorded from a top view (a) and side view (b) simultaneously. The flow field is visualized by using an electrochemical tin-precipitation method. 
not dissolve in $p \mathrm{H}$-neutral water, the small tin-hydroxide particles of $O(1 \mu \mathrm{m})$ form a homogeneous sheet that moves towards the cylinder. With this sheet the wake behind the cylinder is visualized. A detailed description of the visualization method is presented in Ref. 14.

\section{High resolution particle velocimetry}

For the velocity measurements of the wake flow, a HPV technique is applied. HPV is a combination of particle tracking velocimetry and particle image velocimetry. A detailed description of the algorithm is presented in Ref. 18.

In the current investigation, hollow glass particles of size $20 \mu \mathrm{m}$ are used as seeding. These particles are illuminated with the Nd:YAG pulsed laser. For particle tracking velocimetry, a particle path is obtained from a sequence of connected particle locations. From the particle path the velocity vector of the particle is calculated at certain positions and times. Concerning the HPV performance, around 6000 particles are tracked. Since the velocity vectors are randomly distributed, they have to be interpolated onto a regular grid of points. A Gaussian weight function interpolation scheme is used in the current application, in order to calculate the vorticity field. The optimum width of the interpolation window was found to be proportional to the number of seeded vectors. Currently, the width of the interpolation window is between 10 and 20 pixels.

\section{3D spectral element method}

3D numerical simulations are performed using a spectral element method. A convection-diffusion splitting method is used for the time discretization. The convection equation is solved by a three-step explicit Taylor-Galerkin scheme. The diffusion equation is discretized by an implicit second-order backward difference scheme. Within an element, the equations are discretized using a fifth-order spectral method. The computational domain has dimensions length $\times$ height $\times$ width $=15 d \times 7 d \times 4 d$.

For the boundary conditions, a normal velocity of zero is prescribed at the side, top, and bottom walls. At the outflow wall, a normal-stress-free condition is used. Besides, tangential stresses are set to zero at these walls. At the inlet Dirichlet boundary conditions are applied for the velocity components. At the cylinder wall no-slip conditions are applied, while the dimensionless temperature is set to one. A detailed description of the method and the applied boundary conditions can be found in Refs. 19 and 20.

\section{UNHEATED CASE: VORTEX FORMATION}

To have a reference for the vortex shedding process behind a heated cylinder, first the corresponding the unheated case is analyzed. Next the heated case will be analyzed using visualization, HPV, and numerical simulation method.

Extensive descriptive studies of near wake vortex formation for the unheated case come from Refs. 21-23. The hypothesis of Gerrard ${ }^{21}$ says that a forming vortex draws the shear layer (of opposite sign) from the other side of the wake across the wake centerline, eventually cutting off the supply of vorticity to the growing vortex. To some extent this process can be understood from the instantaneous streamline patterns drawn by Perry et al. ${ }^{23}$

To relate the vortex shedding process as described by Gerrard's hypothesis and the drawn patterns of Perry et al. ${ }^{23}$ the wake flow is visualized using particle paths for $\mathrm{Re}=85$ and $\mathrm{Ri}=0$. The flow pattern is considered as $2 \mathrm{D}$.

The "alleyway" can be understood as the trajectory of a fluid particle (path lines) derived by means of tracking the illuminated particles. In Fig. 5 alleyways are shown as solid lines. It was described by Perry et al. ${ }^{23}$ that, during the starting process, the so-called "closed" cavity becomes open and instantaneous alleyways of fluid are formed. In Fig. 5(d) the area around circulation $D$ shows the classical picture of cavity flow. At $t=0$, the cavity is open and instant alleyways of fluid penetrate the cavity. As shown in Fig. 5(a), alleyway of fluid AU from the upper side of the wake enters into the cavity and travels between the cylinder and the vortices. Meanwhile a circulation $B$ (clockwise) is just formed at the upper rear end of the cylinder. The circulation $B$ grows in size and strength with time. At $t=T / 4$, when the AU meets the AL, a stagnation-point flow is formed at the lower part of the near wake. As a result, new alleyways of fluid N1 and N2 are forming around the stagnation point, as shown in Fig. 5(b). From the flow topology, saddle point $S_{L}$ forms just below the circulation $B$, pointing at the formation of a new vortex $B$.

At $t=2 T / 4$, the N2(AL) from the lower side of the wake penetrates the cavity and meets the AU at the upper side of the wake. As the N2 continues to develop, it cuts off the vorticity supply of the growing vortex $B$ from the cylinder wall, as shown in Fig. 5(c). Meanwhile, it is observed that a new circulation $D$ (anticlockwise) appears at the lower rear end of the cylinder.

With the further development, at $t=3 T / 4$, a stagnation point is formed in the upper side of the wake, as shown in Fig. 5(d). New alleyways of fluid (N3 and N4) are forming around the stagnation point, which gradually evolve toward a saddle point. As the circulation $D$ grows bigger and bigger, saddle point $S_{U}$ points to the birth of a new vortex. Furthermore, the N4 joining with the AU cuts off the vorticity supply of the circulation $D$ from the cylinder wall and the process repeats itself.

Thus, the vortex formation of Gerrard's interpretation can be understood as the action of the alleyway of fluid N2. During the vortex shedding process from Fig. 5(b) to 5(c), the N2(AL) cuts off the vorticity supply of the vortex $B$ from the cylinder wall. The hypothesis of Perry et al. ${ }^{23}$ has been reconfirmed that the birth of a new vortex is characterized by the formation of a new saddle point in the streamline topology.

\section{HEATED CASE: FLOW VISUALIZATION}

The influence of a heat input on the wake transition was earlier studied ${ }^{14}$ by an electrochemical tin-precipitation 


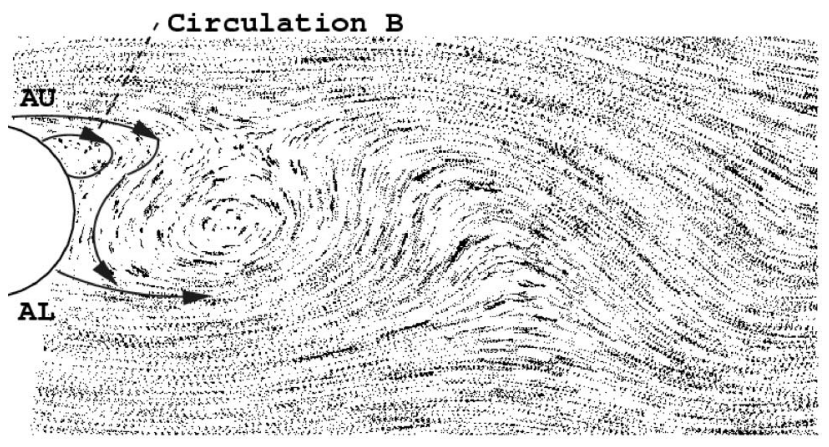

(a) $t=0$

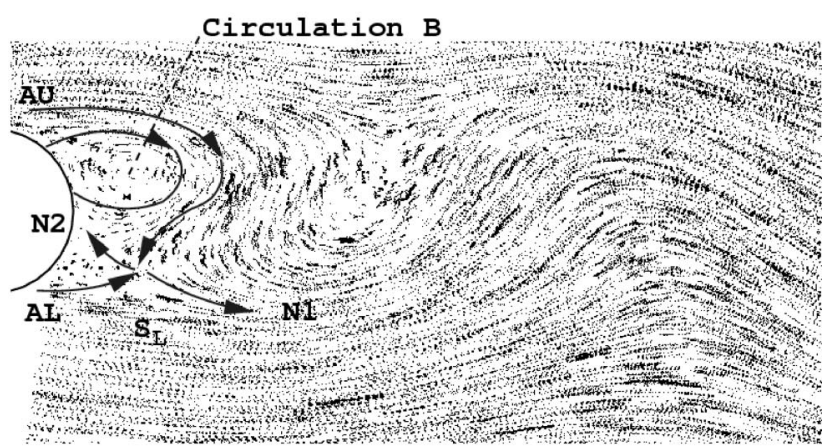

(b) $t=T / 4$

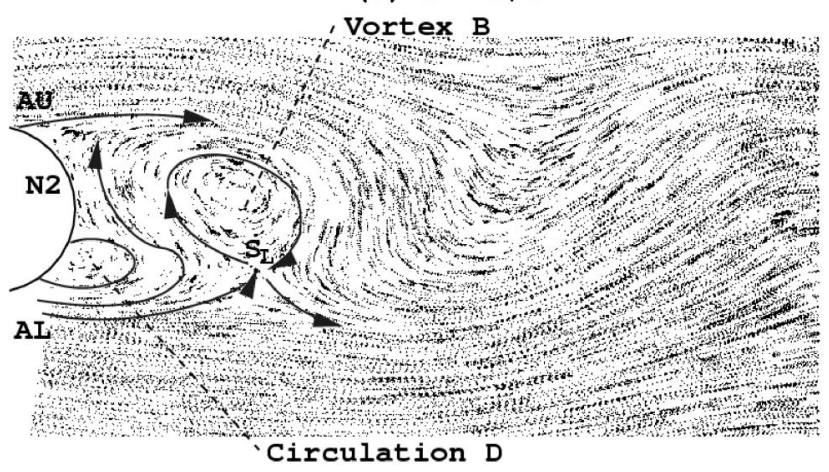

(c) $t=2 \mathrm{~T} / 4$

Vortex B

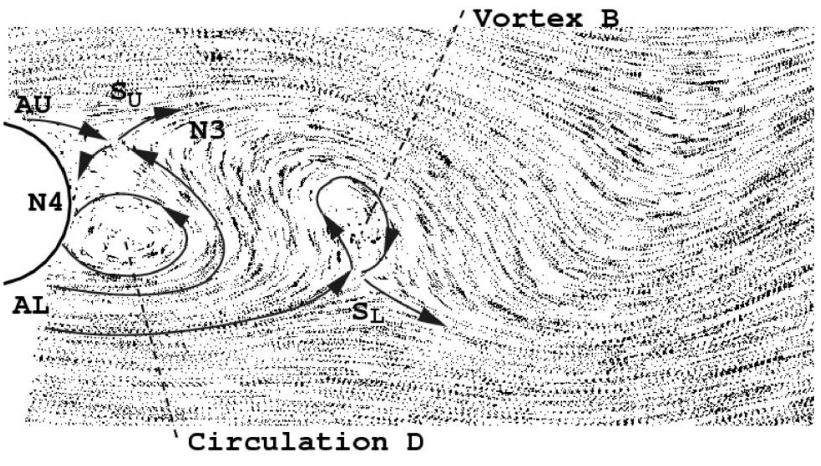

(d) $t=3 \mathrm{~T} / 4$

FIG. 5. The vortex shedding process using particle path lines for $\mathrm{Re}=85$ and $\mathrm{Ri}=0$. The flow pattern has been derived by tracking the illuminated particles. AU and AL are the "alleyways" of fluid from the upper and lower halves of the wake; N1, N2, N3, and N4 are the new generated alleyways of fluid. $S_{U}$ and $S_{L}$ are the saddle points at the upper and lower halves of the wake.

visualization experiment. The experiments were performed at $\operatorname{Re}=117$ and different Richardson numbers. First some earlier visualization results will be shown to introduce the new results.

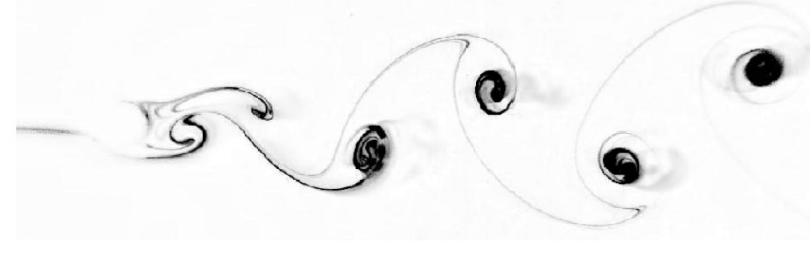

(a) $\mathrm{Ri}=0$

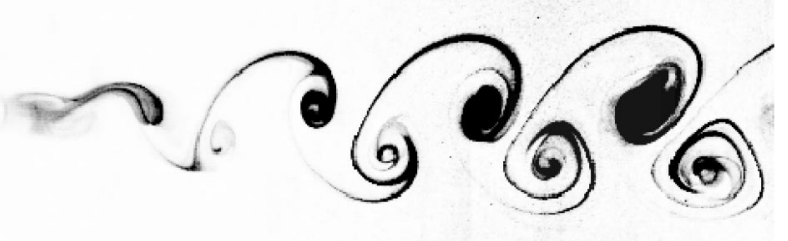

(b) $\mathrm{Ri}=0.4$

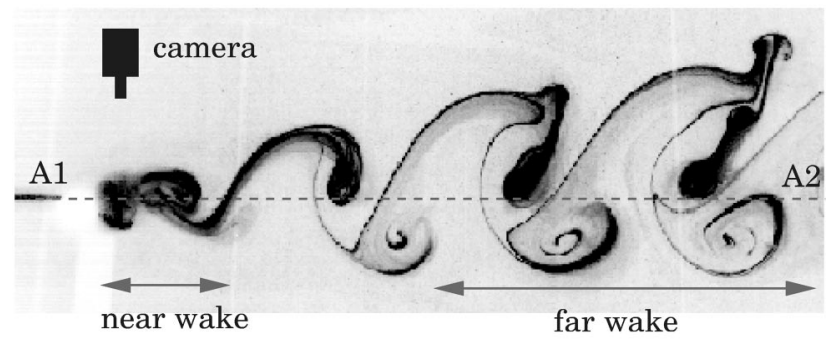

(c) $\mathrm{Ri}=1.0$

FIG. 6. Side view of the wake flow at $\mathrm{Re}=117$ and various Richardson numbers. Flow from left to right. [From Maas et al. (Ref. 14).]

For $\mathrm{Ri}=0$, the wake flow manifests itself as the von Kármán vortex street, as shown in Fig. 6(a). If one increases the input of heat, say to $\mathrm{Ri}=0.4$, the wake still resembles more or less the von Kármán vortex street, as shown in Fig. 6(b). Generally, for $\mathrm{Ri}<1$, the hot fluid is initially captured in the core of the shed vortices, and only diffusion processes can cause it to spread. Because water is used as the working fluid, the diffusion takes place relatively slow and the vortex street remains primarily two-dimensional.

If one again increases the heat input, for $\mathrm{Ri} \geqslant 1$ the upward buoyancy force seems to change the flow pattern of the upper vortices. Thermal plumes are being formed and escape in the far wake, as shown in Fig. 6(c). When the camera is positioned above the cylinder, the corresponding top view is presented. It clearly shows the development of the escaping thermal plumes for $\mathrm{Ri}=1.0$, as shown in Fig. 7. It is observed that the thermal plumes are initiated in the near wake and escape from the upper vortices in the far wake. The thermal plumes occur at spanwise positions with a distance of around twice the cylinder diameter.

To understand the formation of the thermal plumes, detailed visualizations are conducted in the near wake. A horizontal laser sheet is created cutting the centerline of the wake with the camera positioned perpendicular to this sheet [indicated in Fig. 6(c) as intersection A1-A2]. It is observed that pairs of counterrotating vortices (CRV) appear directly behind the cylinder, as shown in Fig. 8. The distance between the CRV is exactly the same as the distance between the plumes, being twice the cylinder diameter. Furthermore, a 


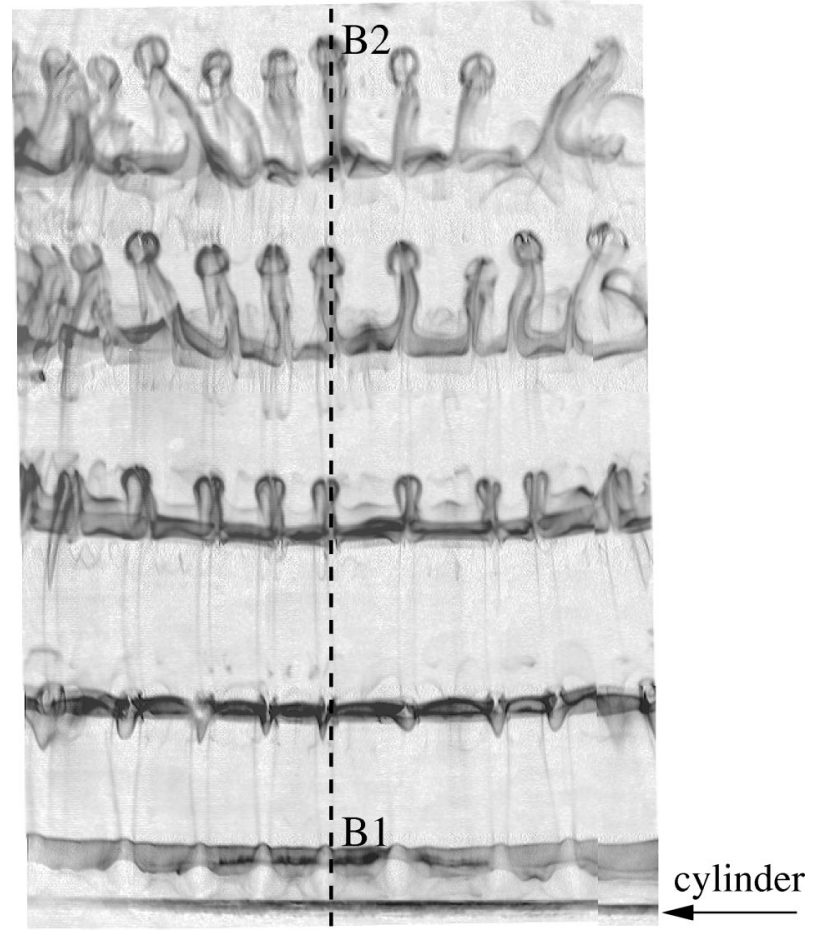

FIG. 7. Top view of the flow pattern behind the cylinder for $\mathrm{Ri}=1.0$ and $\operatorname{Re}=117$. [From Maas et al. (Ref. 14).]

spanwise waviness is observed both in the vortices and the braids. Likewise, the spanwise positions of the CRV determine the positions at which the thermal plumes escape in the far wake. The observations suggest a strong link between the escaping thermal plumes and the CRV occurring in the near wake.

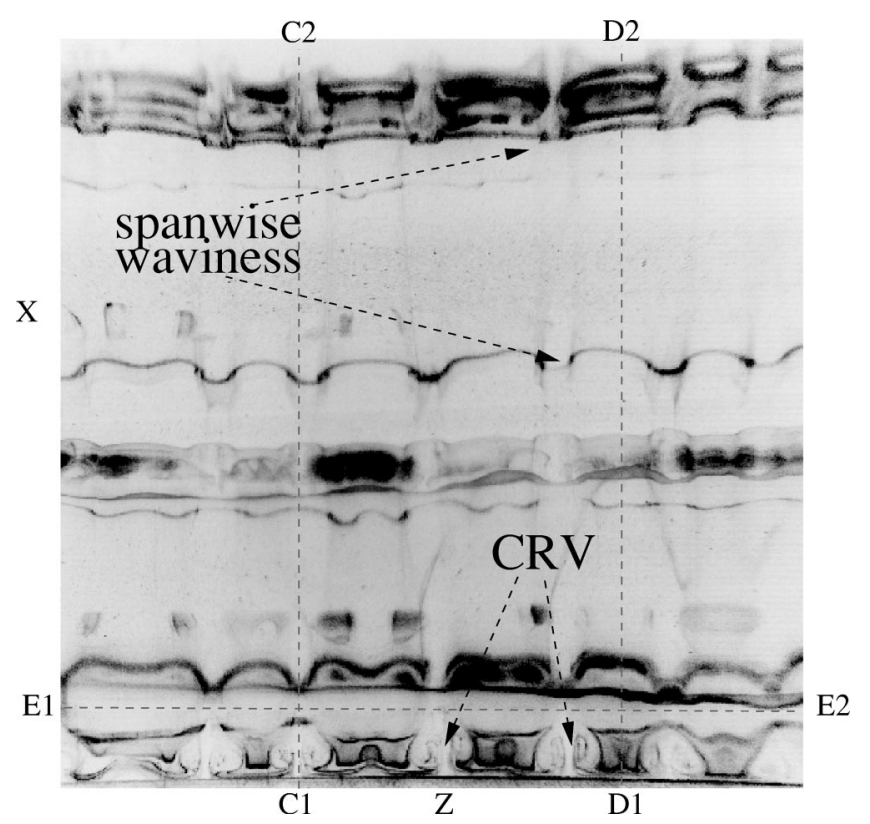

FIG. 8. Visualization of the counterrotating vortices in the intersection A1A2. Flow from bottom to top. (CRV stands for counterrotating vortices.)
As indicated in Fig. 8, the intersection $\mathrm{C} 1-\mathrm{C} 2$ is referred to as "in-plume," which corresponds to intersection B1-B2 in Fig. 7. Similarly, the intersection D1-D2 is referred to as "out-of-plume."

\section{HEATED CASE: HPV MEASUREMENTS}

To get a more detailed understanding, the velocity fields in the $x-y$ plane are measured for $\mathrm{Re}=85$ and $\mathrm{Ri}=1.0$ using the HPV technique. In Figs. 9 and 10, velocity fields at outof-plume and in-plume positions are presented, respectively, as a function of time. Streamline patterns are obtained from the velocity fields. The dimensions shown in Figs. 9 and 10 are based on the cylinder diameter. In the remainder of the text all dimensions are scaled with the cylinder diameter.

In Fig. 9, the development of the wake flow at an outof-plume position is shown as a function of time. It is seen that at $t=0$ a circulation $B$ appears at the upper rear end of the cylinder, as shown in Fig. 9(a). This circulation $B$ grows with time. At $t=T / 4$, a saddle point $S_{L}$ locates around $x$ $=1.0$ just below the circulation $B$, pointing at the birth of an upper vortex, as shown in Fig. 9(b). At $t=2 T / 4$, a forming vortex $B$ draws the shear layer from the lower side of the wake across the centerline of the wake, and cuts off the vorticity supply from the cylinder wall, as shown in Fig. 9(c). With the further development of the vortex shedding, a new circulation $D$ (anticlockwise) is formed at the lower rear end of the cylinder. The new circulation $D$ grows bigger and bigger. At $t=3 T / 4$, a new saddle point $S_{U}$ points to the birth of a lower vortex, as shown in Fig. 9(d). A new separation point appears at the upper rear of the cylinder and the process repeats itself. The vortex shedding process for the outof-plume position is quite similar to the one for an unheated cylinder (Fig. 5), which is a two-dimensional flow.

In Fig. 10, the velocity fields at an in-plume position are presented as a function of time. We observe that the vortex shedding process at the in-plume position is quite different from the one at the out-of-plume position.

First of all for $t=0$, it is observed that there is a stagnation region near the lower rear end of the cylinder, as shown in Fig. 10(a). Second, in Fig. 10(b) it is observed that the formation of the saddle point $S_{L}$ is located around $x=1.5$, while for the out-of-plume position the location of the saddle point $S_{L}$ is around $x=1.0$, as shown in Fig. 9(b). Third, a strong upward motion is observed in the near wake, as shown in Fig. 10(c). There is almost no circulation behind the cylinder. Furthermore, at $t=3 T / 4$ a circulation $D$ is located around the center of the wake, as shown in Fig. 10(d), while for the out-of-plume position the circulation $D$ is located at the upper rear end of the cylinder and the saddle point $S_{U}$ is formed above the vortices, as shown in Fig. 9(d).

Unlike the mechanism of the vortex shedding for the out-of-plume positions, the formation of the vortices at the in-plume positions is not symmetrical between the upper and lower halves of the wake in one vortex shedding cycle. We observe that there is a strong upward motion in the near wake. This upward motion enhances the formation of the upper vortices and weakens the formation of the lower ones. 

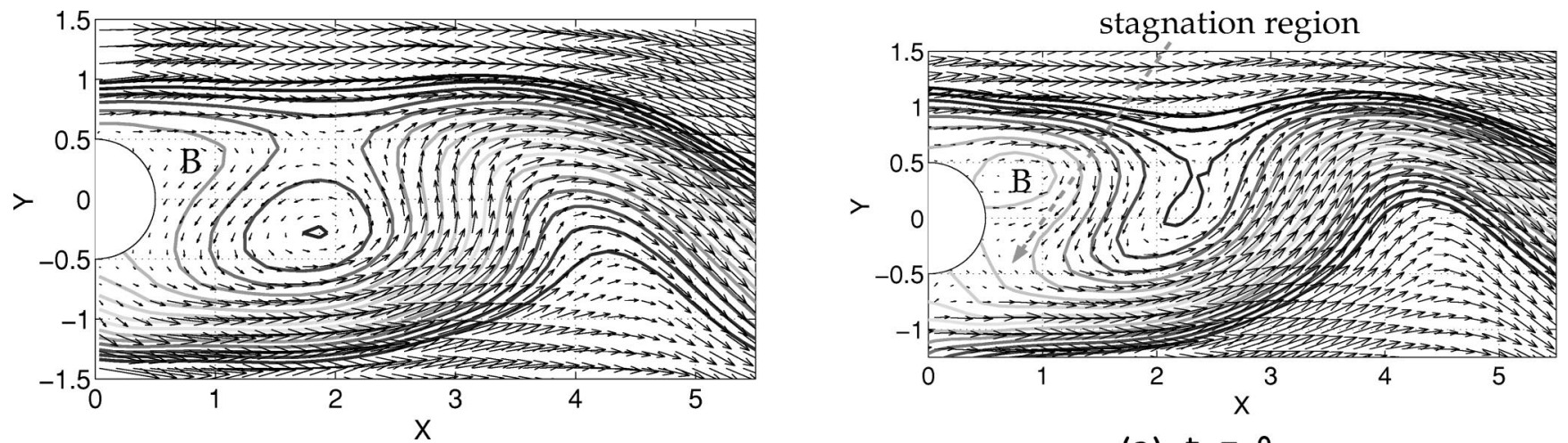

(a) $t=0$

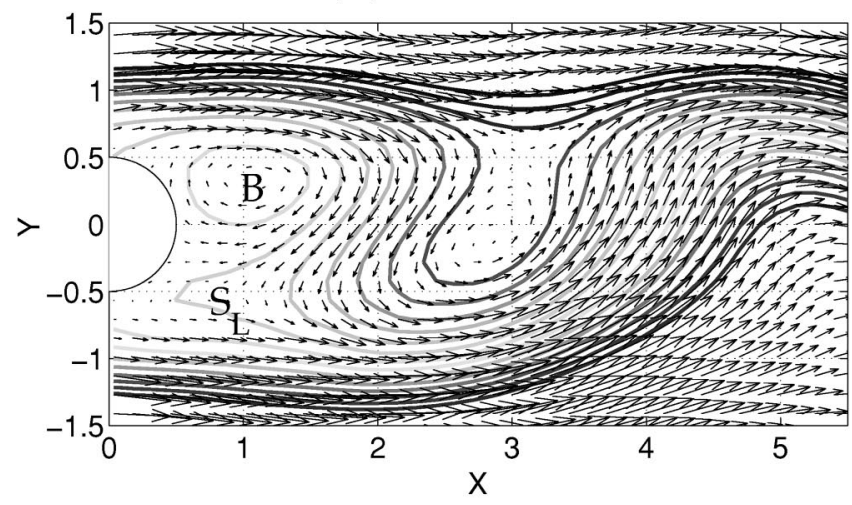

(b) $t=T / 4$

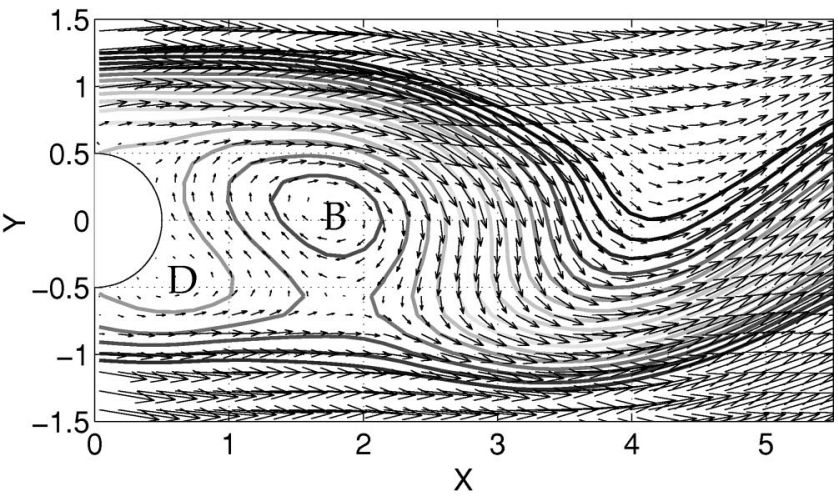

(a) $t=0$

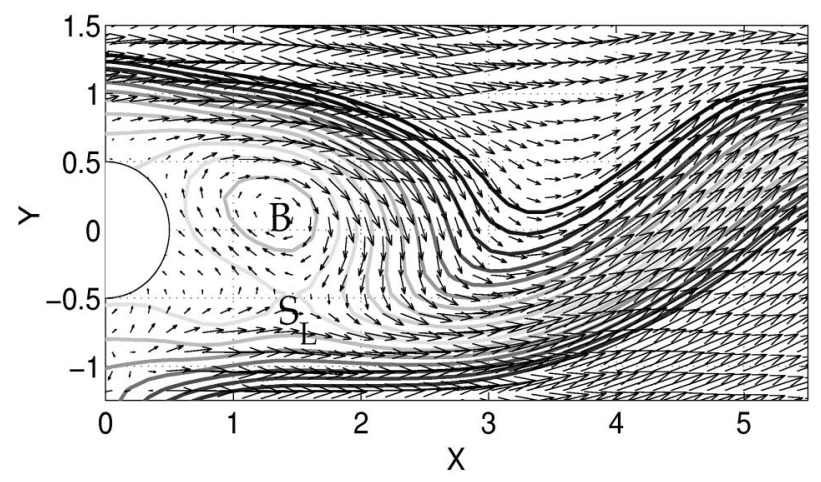

(b) $t=T / 4$

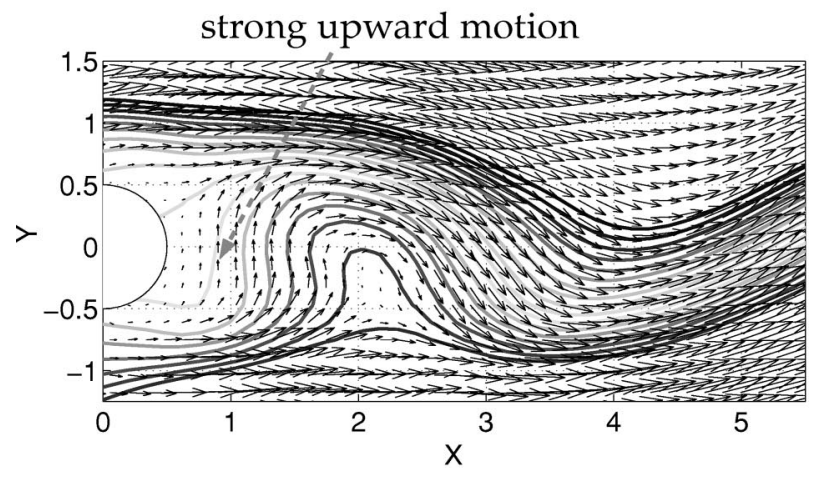

(c) $t=2 \mathrm{~T} / 4$

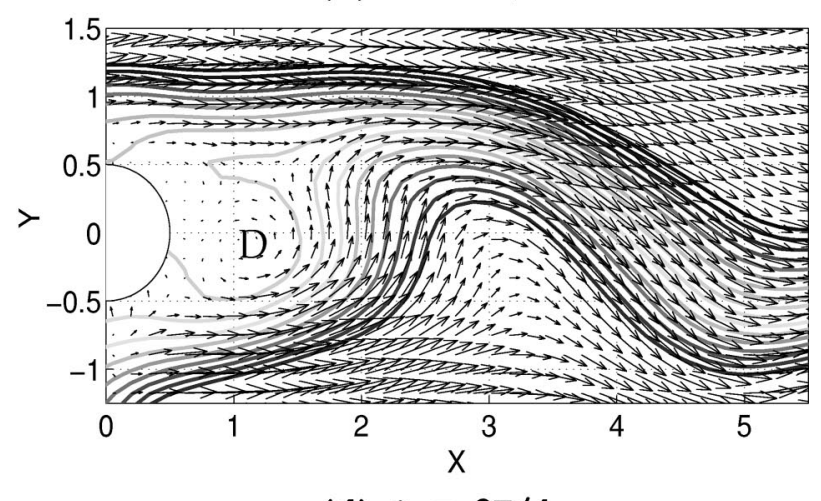

(d) $t=3 T / 4$

FIG. 10. Velocity vectors and streamlines at "in-plume" position for Re $=85$ and $\mathrm{Ri}=1.0$ obtained by using HPV technique. $B$ and $D$ are circulation areas at the upper and lower halves of the wake. $S_{L}$ is the saddle point at the lower half of the wake.

\section{HEATED CASE: NUMERICAL INVESTIGATIONS}

A 3D-SEM simulation provides detailed insight into the $\mathrm{Re}=85$ and $\mathrm{Ri}=1.0$ obtained by using HPV technique. $B$ and $D$ are circulation areas at the upper and lower halves of the wake. $S_{U}$ and $S_{L}$ are the saddle points at the upper and lower halves of the wake.

vortex shedding process behind a heated cylinder. The simu- 

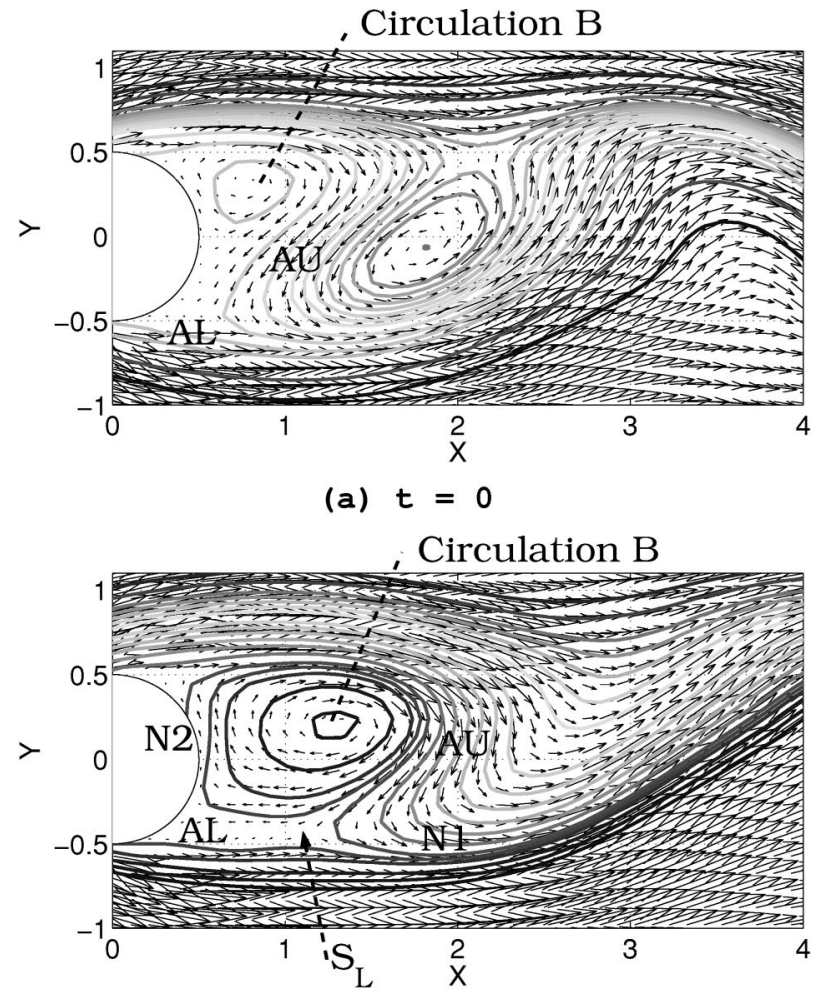

(b) $t=T / 4$

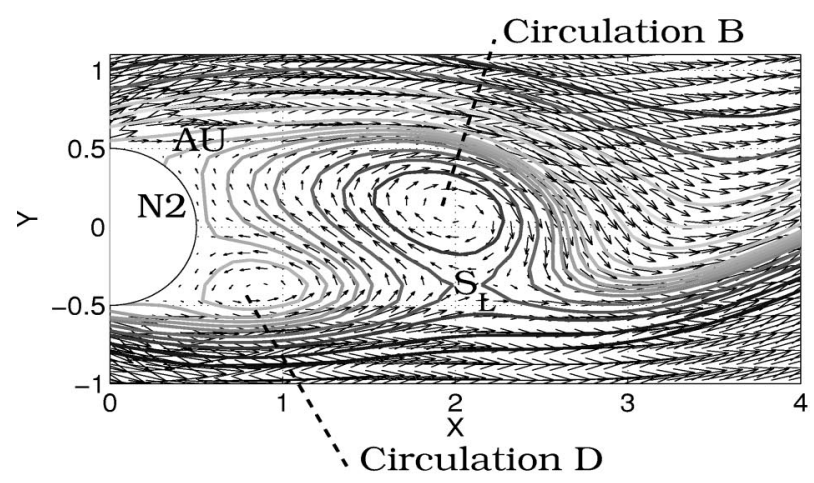

(c) $t=2 \mathrm{~T} / 4$

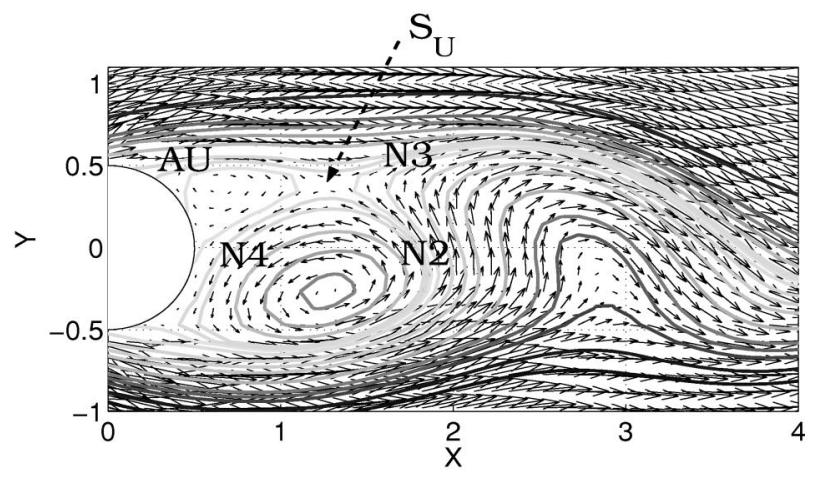

(d) $t=3 \mathrm{~T} / 4$

FIG. 11. Calculated velocity fields and streamlines at an "out-of-plume" position at $\mathrm{Re}=85$ and $\mathrm{Ri}=1.0 . \mathrm{AU}$ and $\mathrm{AL}$ are the "alleyways" of fluid from the upper and lower halves of the wake; N1 and N2 are the new generated alleyways of fluid. $B$ and $D$ are circulation areas at the upper and lower halves of the wake. $S_{U}$ and $S_{L}$ are the saddle points at the upper and lower halves of the wake.

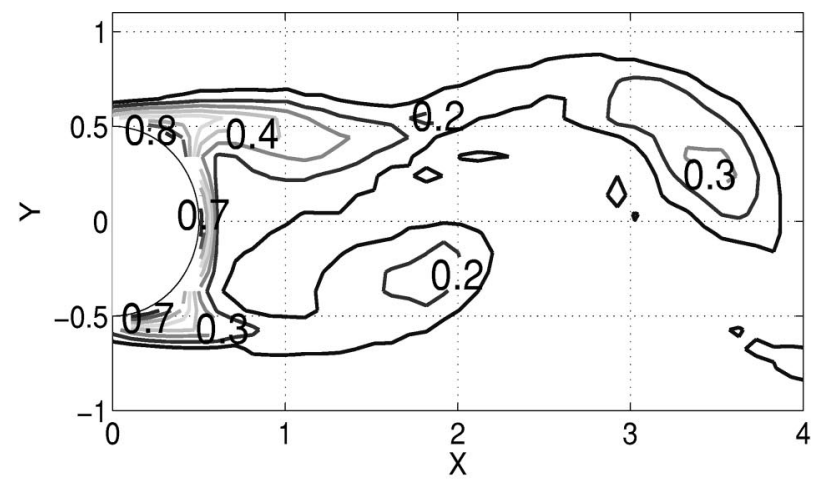

(a) $t=0$

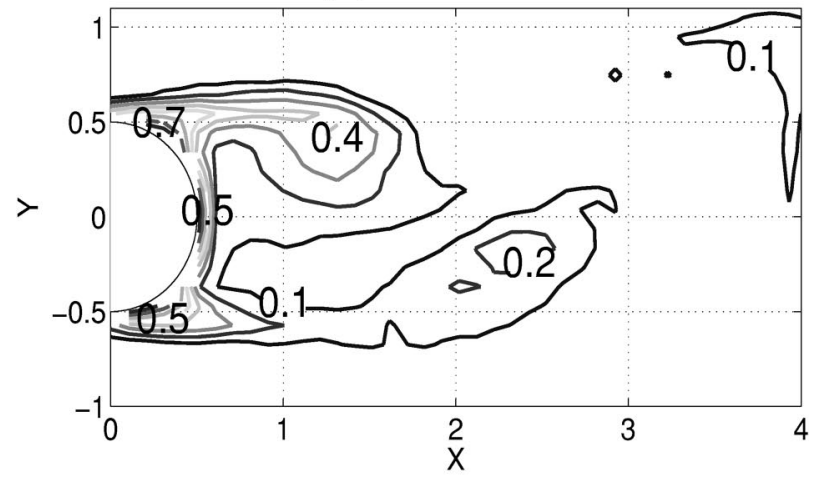

(b) $t=T / 4$

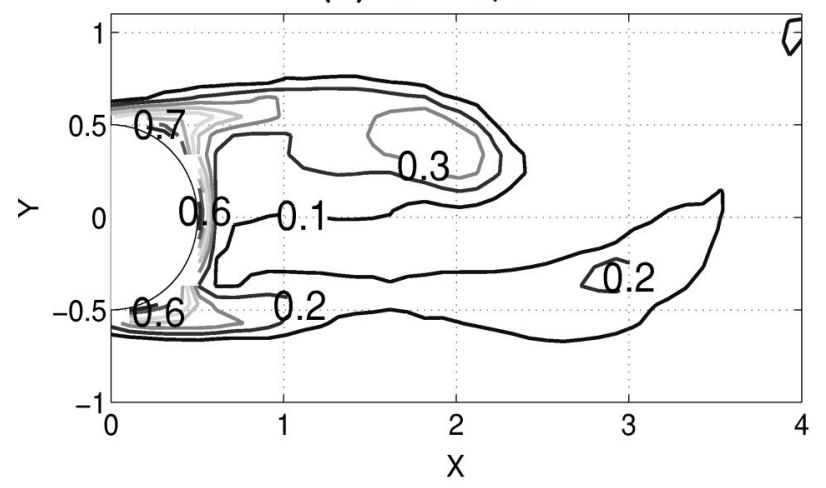

(c) $t=2 \mathrm{~T} / 4$

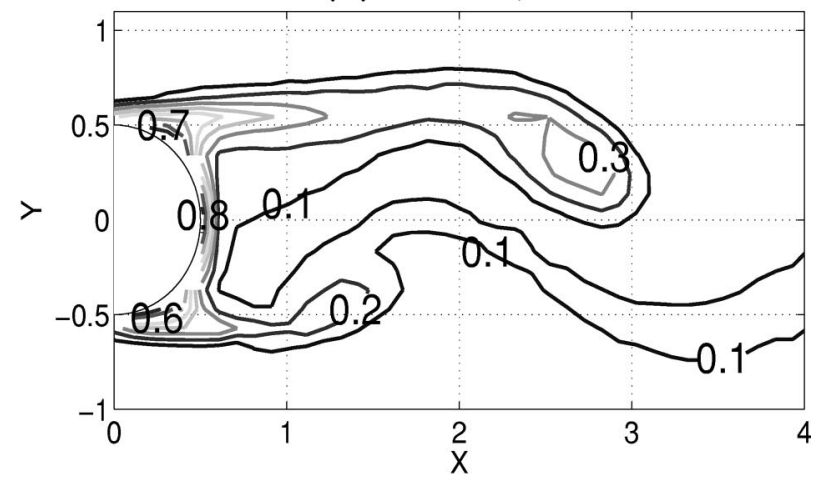

(d) $t=3 \mathrm{~T} / 4$

FIG. 12. Calculated isotemperature lines at an "out-of-plume" position at $\mathrm{Re}=85$ and $\mathrm{Ri}=1.0$. Numbers indicate temperature values.

lation is performed at $\mathrm{Re}=85$ and $\mathrm{Ri}=1.0$. In Figs. 11 and 12 the velocity and temperature fields are presented at an out-of-plume position. In Figs. 13 and 14 the velocity and temperature fields are presented at an in-plume position. 


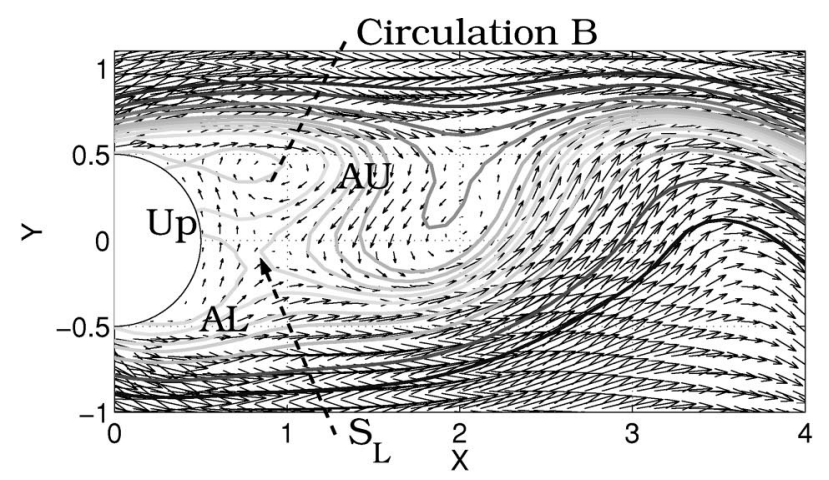

(a) $t=0$

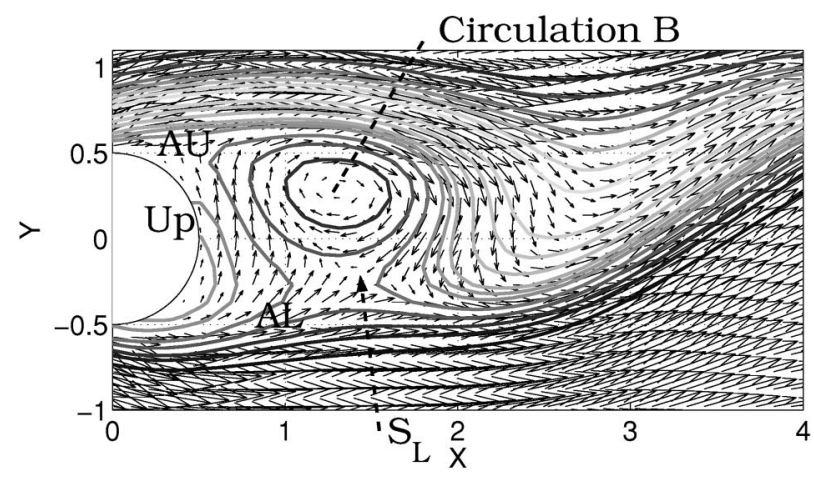

(b) $t=T / 4$

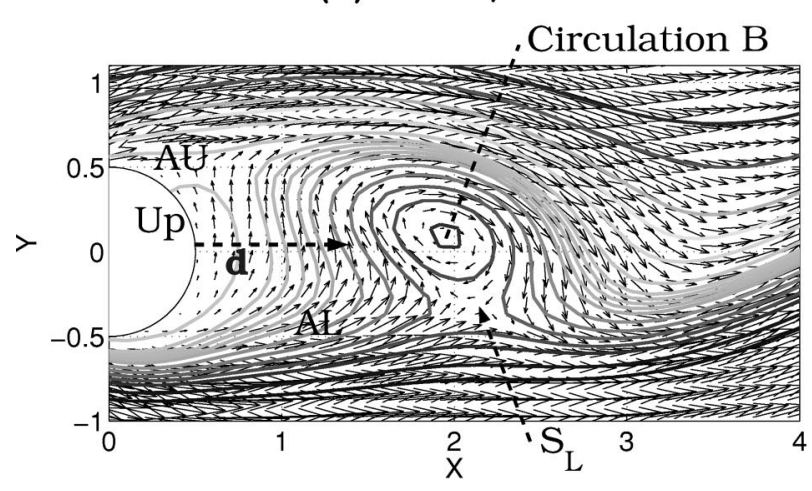

(c) $t=2 \mathrm{~T} / 4$

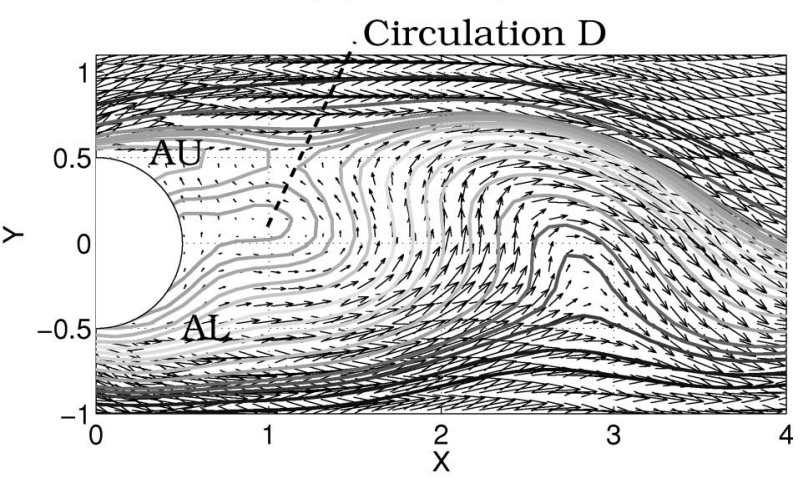

(d) $t=3 T / 4$

FIG. 13. Calculated velocity fields and streamlines at an "in-plume" position at $\mathrm{Re}=85$ and $\mathrm{Ri}=1.0$. $\mathrm{AU}$ and $\mathrm{AL}$ are the "alleyways" of fluid from the upper and lower halves of the wake; $U$ p indicates the alleyway of fluid with upward motion. $B$ and $D$ are circulation areas at the upper and lower halves of the wake. $S_{L}$ is the saddle point at the lower half of the wake.

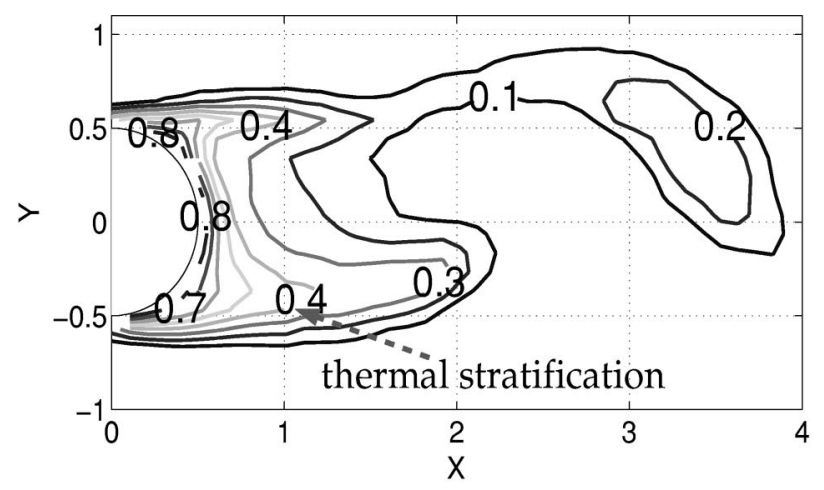

(a) $t=0$

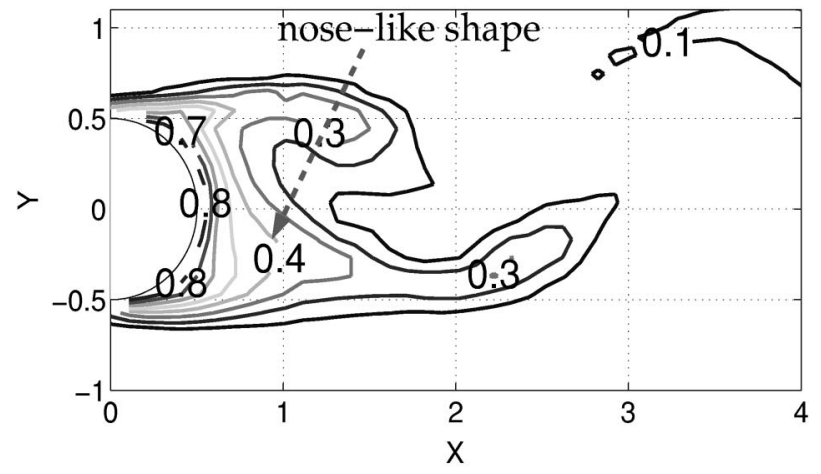

(b) $t=T / 4$

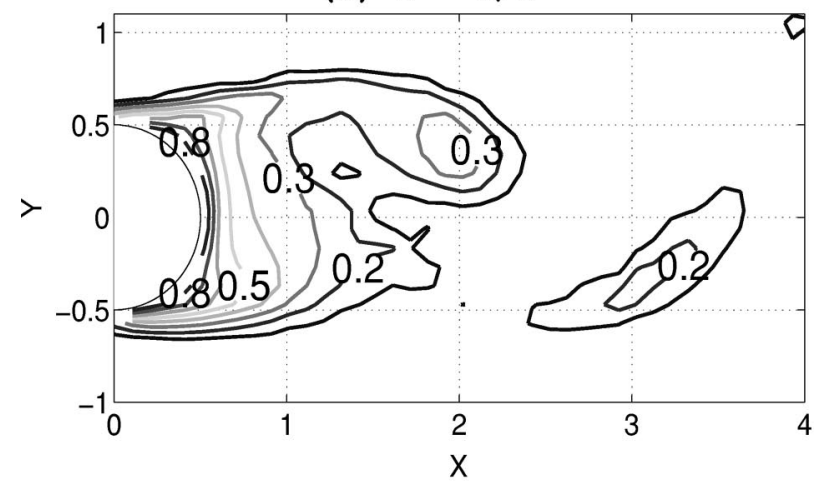

(c) $t=2 \mathrm{~T} / 4$

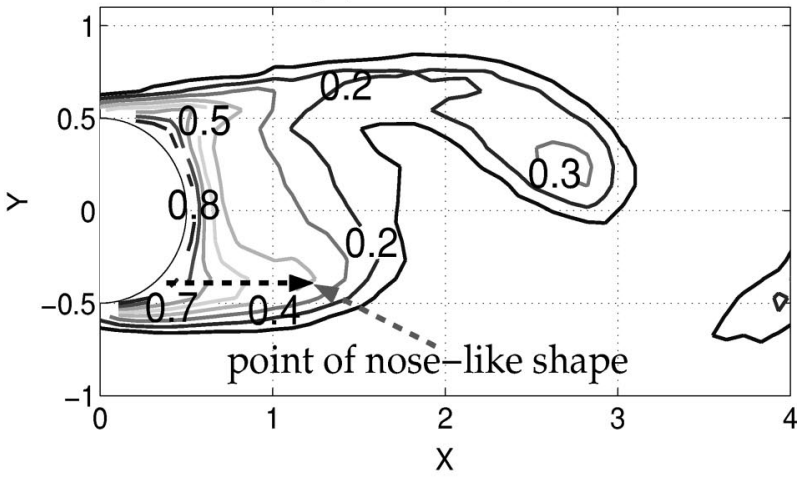

(d) $t=3 \mathrm{~T} / 4$

FIG. 14. Calculated isotemperature lines at an "in-plume" position at Re $=85$ and $\mathrm{Ri}=1.0$. Numbers indicate temperature values.

Streamline patterns are obtained from the calculated $2 \mathrm{D}$ velocity fields. Although we realize that the 3D flow motion is not incorporated, we feel that the shown streamlines are illustrative. 


\section{A. Vortex shedding process at "out-of-plume" position}

In Fig. 11, the vortex shedding process at an out-ofplume position is shown in one vortex shedding cycle. It is observed that the calculated velocity fields show a good agreement with the measured velocity fields.

At $t=0$ the instantaneous alleyway of fluid AU from the upper side of the wake penetrates the cavity. Meanwhile, a circulation $B$ appears at the upper rear end of the cylinder, as shown in Fig. 11(a). This circulation $B$ grows with time. At $t=T / 4$, when the AU meets alleyway of fluid AL, a stagnation point is formed around $x=1.0$ at the lower side of the wake. New alleyways of fluid N1 and N2 are forming around the stagnation point, as shown in Fig. 11(b). A saddle point $S_{L}$ points at the birth of an upper vortex. At $t=2 T / 4$, a forming vortex $B$ draws the shear layer (N2) from the lower side of the wake and cuts off the vorticity supply of vortex $B$ from the cylinder wall. Furthermore, a new circulation $D$ (anticlockwise) is formed at the lower rear end of the cylinder, as shown in Fig. 11(c). The new circulation $D$ grows bigger and bigger. At $t=3 T / 4$, a new saddle point $S_{U}$ points to the birth of a vortex, as shown in Fig. 11(d). A new circulation appears at the upper rear of the cylinder and the process repeats itself.

In Fig. 12, the calculated temperature fields show that the hot fluid resides mostly inside the vortices. The numbers indicate the temperature values. It is observed that the temperature distribution in the upper and lower halves of the wake is more or less symmetrical in one vortex shedding cycle, although the temperatures in the upper vortices are slightly higher than in the lower ones.

\section{B. Vortex shedding process at "in-plume" position}

In Fig. 13, the calculated vortex shedding process is shown at an in-plume position as a function of time. Also here the calculated velocity fields show a good agreement with the measured velocity fields.

We observe that the vortex formation process is different from the one for the out-of-plume position. At $t=0$ an upward motion (alleyway of fluid $U \mathrm{p}$ ) is forming near the cylinder wall. This upward motion meets the alleyway of fluid $\mathrm{AU}$ around the centerline of the wake. A saddle point $S_{L}$ is positioned below circulation $B$ just after it starts to grow. Thus vortex $B$ is already formed when the vortex shedding process begins, as shown in Fig. 13(a). At the out-of-plume position the formation of vortex $B$ is somewhat later, around $t=T / 4$, as observed in Fig. 11(b).

At $t=T / 4$, the saddle point $S_{L}$ is located around $x$ $=1.5$, as shown in Fig. 13(b). While for the out-of-plume position, the streamwise position of the saddle point $S_{L}$ is around $x=1.0$, as shown in Fig. 11(b). The difference could result in a spanwise waviness of the primary vortices, as observed in Fig. 8.

In Figs. 13(a) and 13(b), the upward motion already separates the upper vortex from the cylinder wall. By cutting off the vorticity supply of vortex $B$ from the cylinder wall, the upward motion enhances the formation of the upper vortices.
At $t=2 T / 4$, a large area of upward motion is observed in the near wake. The thickness $d$ of this upward motion is around one cylinder diameter, as shown in Fig. 13(c). Furthermore, it is observed that there is almost no circulation behind the cylinder. At $t=3 T / 4$ a circulation area around point $D$ is located around the center of the wake, as shown in Fig. 13(d).

From the temperature fields, it is observed that the hot fluid has been accumulated in the near wake. As shown in Figs. 14(a) and 14(b), the temperature distribution in the lower half has a nose-like shape (for example, the contour of $\Theta=0.4$ at $t=T / 4)$. It is observed that the point of the noselike shape becomes longer and longer with time. At $t$ $=3 T / 4$, the distance between the point of the nose-like shape and the cylinder is around one cylinder diameter, as shown in Fig. 14(d). An unstable thermal stratification in gravity direction starts to grow around the point of the nose-like shape, where the warm fluid is below the cold one, as shown in Fig. 14(a). Around $x=1.0$, if the temperature difference is large enough, the buoyancy force becomes dominant and this results in a flow from the lower to the upper half of the wake, as shown in Figs. 13(a) and 13(b).

\section{Flow pattern at intersection $x=1$}

To understand the 3D vortical structures in the near wake, the velocity and temperature fields are studied at intersection $E 1-E 2$. This intersection $E 1-E 2$ is located at $x$ $=1$, as indicated in Fig. 8. In Figs. 15 and 16, the calculated velocity ( $y$ and $z$ components) and temperature fields are shown for $\mathrm{Re}=85$ and $\mathrm{Ri}=1.0$. Streamline patterns are obtained from the calculated velocity fields. The in-plume position is situated at $z=-2$, while the out-of-plume positions are situated at $z=-1$ and $z=-3$.

In Fig. 15(a), we observe a pair of streamwise counterrotating vortices $\left(\omega_{x}\right)$ around $z=-2$. These streamwise counterrotating vortices seem to originate from the upward motion at the in-plume position. Furthermore, secondary flows (divergent flows and convergent flows) are observed at the upper and lower sides of the wake at the in-plume positions, as shown in Fig. 15(b). Likewise, we also observe that the flow moves from the lower to the upper half of the wake. This corresponds to the observation in Fig. 13(c).

From the temperature field it is observed that there is a hot fluid accumulation for the in-plume position, as shown in Fig. 16(a). Besides, there is an unstable thermal stratification in gravity direction at $z=-2$, as shown in Fig. 16(b). This thermal stratification corresponds to the observation in Fig. 14(c) for the in-plume position. When the temperature difference is large enough in gravity direction, an upward flow can be induced by buoyancy.

Likewise, there is a nonuniform temperature distribution along the spanwise direction. Fluid with a high temperature is accumulated at the in-plume positions and fluid with low temperature is at the out-of-plume positions.

\section{CONCLUSION}

The mechanism of the vortex formation behind a heated cylinder has been investigated at a low Reynolds number 


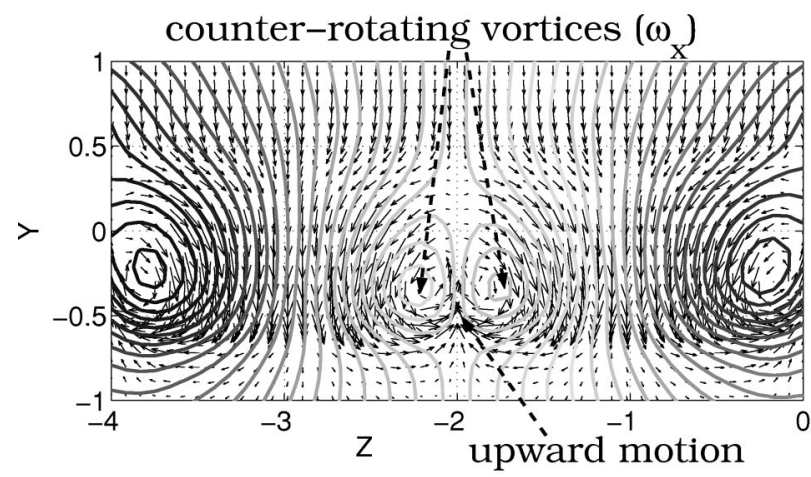

(a) $t=0$

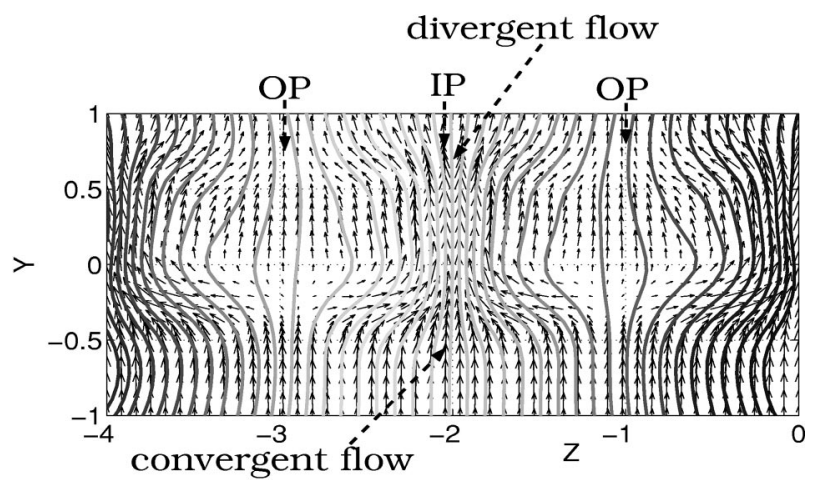

(b) $t=2 T / 4$

FIG. 15. Calculated velocity fields and streamlines at intersection $x=1$ for $\mathrm{Re}=85$ and $\mathrm{Ri}=1.0$. (IP and OP indicate the "in-plume" and the "out-ofplume" positions, respectively. The in-plume position is situated at $z=-2$; the out-of-plume positions are situated at $z=-1$ and $z=-3$.)

$(\mathrm{Re}=85)$. For $\mathrm{Ri}=0$ (unheated case), the flow pattern is two dimensional. When the starting process begins, the so-called closed cavity becomes open and instantaneous alleyways of fluid penetrate the cavity. The vortex formation is characterized by the shear layer from the other side of the wake cutting off the vorticity supply to the growing vortex from the cylinder wall, just as stated by Gerrard. ${ }^{21}$ From a flow topology, the birth of a new vortex is associated with the formation of a saddle point, as earlier found by Perry et al. ${ }^{23}$

For $\mathrm{Ri}=1.0$, it is observed that pairs of counterrotating vortices appear directly behind the cylinder. The distance between the counterrotating vortices is exactly the same as the distance between the plumes, being twice the cylinder diameter. The observations suggest a strong link between the counterrotating vortices occurring in the near wake and the escaping thermal plumes in the far wake. Velocity measurements and numerical calculations showed that the mechanism of the vortex shedding for the out-of-plume position is quite different from the one for the in-plume position. It is observed that the shedding process for the out-of-plume position is quite similar to the one for an unheated cylinder. For the in-plume positions, the formation of the saddle point in the upper and lower sides of the wake is not symmetrical in one vortex shedding cycle. Furthermore, at the in-plume positions, an upward motion occurs directly behind the cylinder which separates the vortices from the cylinder wall. It is observed that an upward motion near the cylinder wall en-

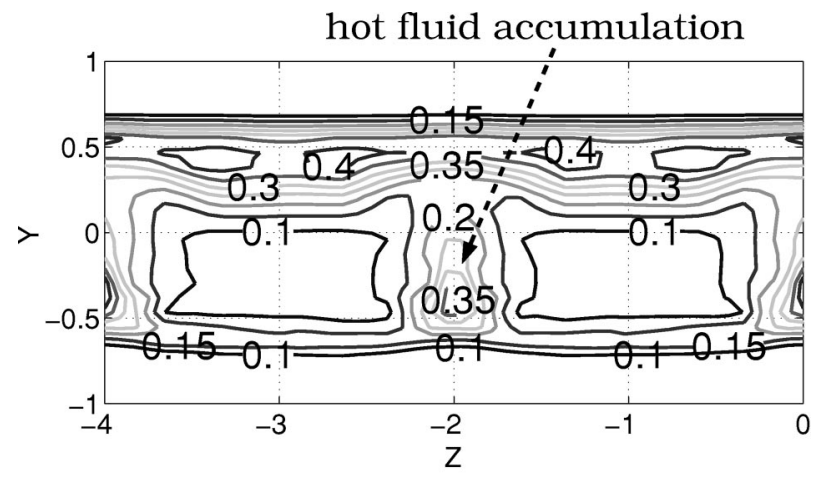

(a) $t=0$

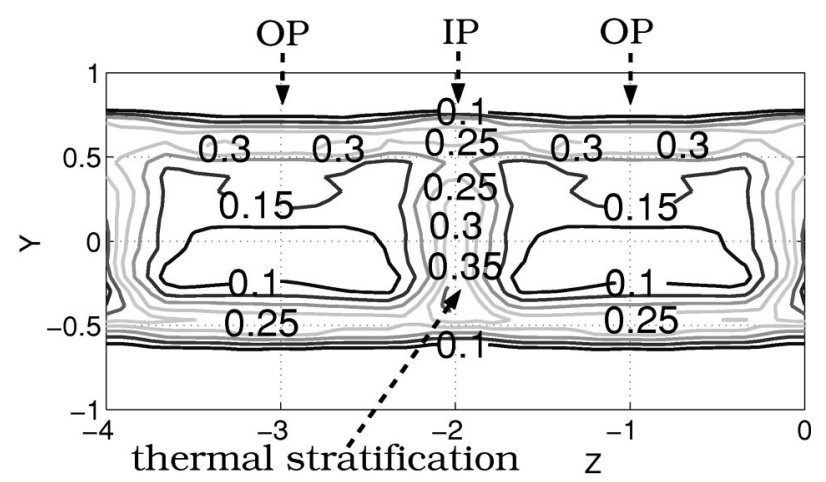

(b) $t=2 T / 4$

FIG. 16. Calculated isotemperature lines at intersection $x=1$ for $\operatorname{Re}=85$ and $\mathrm{Ri}=1.0$. Numbers indicate temperature values. (IP and OP indicate the "in-plume" and the "out-of-plume" positions, respectively. The in-plume position is situated at $z=-2$; the out-of-plume positions are situated at $z$ $=-1$ and $z=-3$.)

hances the formation of the upper vortices and weakens the formation of the lower ones. The calculated velocity fields show a good agreement with the measured ones.

From the calculated temperature fields it is shown that hot fluid has been accumulated at the in-plume positions. Consequently, an unstable thermal stratification in gravity direction is observed. Furthermore, the flow moves from the lower to the upper half of the wake. When the temperature difference is large enough in gravity direction, the upward flow motion can be induced by buoyancy. Likewise, a nonuniform temperature distribution is observed in spanwise direction.

\section{ACKNOWLEDGMENTS}

This work was part of the research programs of the Netherlands Foundation for Fundamental Research on Matters (FOM), which is financially supported by the Netherlands Organization for Scientific Research (NWO). The authors would like to thank the secretaries and technical staff of the Laboratory for Energy Technology of the Department of Mechanical Engineering at Eindhoven University of Technology for their support.

${ }^{1}$ C. H. K. Williamson, "Three-dimensional wake transition," J. Fluid Mech. 328, 345 (1996).

${ }^{2}$ R. Mittal and S. Balachander, "Generation of streamwise vortical structures in bluff-body wake,” Phys. Rev. Lett. 75, 1300 (1995). 
${ }^{3}$ A. Roshko, "On the wake and drag of bluff bodies," J. Aeronaut. Sci. 22, 124 (1955)

${ }^{4}$ F. R. Hama, "Three-dimensional vortex pattern behind a circular cylinder," J. Aeronaut. Sci. 24, 156 (1957).

${ }^{5}$ J. H. Gerrard, "The wakes of cylinder bluff bodies at low Reynolds number,' Philos. Trans. R. Soc. London, Ser. A 288, 351 (1978).

${ }^{6}$ C. H. K. Williamson, "The existence of two stages in the transition to three-dimensionality of a cylinder wake," Phys. Fluids 31, 3165 (1988).

${ }^{7}$ K. Noto, M. Ishida, and R. Matsumoto, "A break-down of the von Karman vortex street due to the natural convection," in Flow Visualization III, edited by W. J. Yang (Springer, New York, 1983), p. 348.

${ }^{8} \mathrm{~K}$. Noto, "Computational investigation on wake behavior with buoyancy from a heated elliptic cylinder: Effect of mainstream attack angle," in Proceedings of 39th Japanese National Congress of Applied Mechanics (University of Tokyo Press, Tokyo, 1990), pp. 293-303.

${ }^{9}$ J. C. Lecordier, L. Hamma, and P. Paranthoen, "The control of vortex shedding behind heated circular cylinders at low Reynolds number,' Exp. Fluids 10, 224 (1991).

${ }^{10}$ A. Wang, Z. Travnicek, and K. Chia, "On the relationship of effective Reynolds number and Strouhal number for the laminar vortex shedding of a heated circular cylinder,' Phys. Fluids 12, 1401 (2000).

${ }^{11}$ R. N. Kieft, C. C. M. Rindt, and A. A. van Steenhoven, "Heat induced transition of a stable vortex street," Int. J. Heat Mass Transfer 45, 2739 (2002).

${ }^{12}$ R. N. Kieft, C. C. M. Rindt, A. A. van Steenhoven, and G. J. F. van Heijst, "On the wake structure behind a heated horizontal cylinder in cross-flow," J. Fluid Mech. 486, 189 (2003).

${ }^{13}$ A. A. van Steenhoven and C. C. M. Rindt, "Flow transition behind a heated cylinder," Int. J. Heat Fluid Flow 24, 322 (2003).

${ }^{14}$ W. J. P. M. Maas, C. C. M. Rindt, and A. A. van Steenhoven, "The influence of heat on the 3D-transition of the von Karmán-vortex street," Int. J. Heat Mass Transfer 46, 3069 (2003).

${ }^{15}$ M. Ren, C. C. M. Rindt, and A. A. van Steenhoven, "The influence of heat on the 3D-transition of the cylinder wake flow," in Proceedings 12th International Heat Transfer Conference, Grenoble, France, edited by J. Taine (Elsevier, New York, 2002), pp. 429-434.

${ }^{16}$ R. N. Kieft, "Mixed convection behind a heated cylinder," Ph.D. thesis, Eindhoven University of Technology, 2000.

${ }^{17}$ M. Ren, C. C. M. Rindt, and A. A. van Steenhoven, "3D vortices in the wake flow behind a heated cylinder," in Proceedings of EUROTHERM 74 in Heat Transfer in Unsteady and Transitional Flows, edited by H. C. de Lange and A. A. van Steenhoven (Eindhoven, The Netherlands, 2003).

${ }^{18}$ R. J. M. Bastiaans, G. A. J. van der Plas, and R. N. Kieft, "The performance of a new PTV algorithm applied in super-resolution PIV,' Exp. Fluids 32, 346 (2002).

${ }^{19}$ L. J. P. Timmermans, P. D. Minev, and F. N. van de Vosse, "An approximate projection scheme for incompressible flow using spectral elements," Int. J. Numer. Methods Fluids 22, 673 (1996).

${ }^{20}$ M. Ren, C. C. M. Rindt, and A. A. van Steenhoven, "Buoyancy induced 3D-transition behind a heated cylinder," in Proceedings of Third International Symposium on Turbulence and Shear Flow Phenomena, Sendai, Japan, 2003

${ }^{21}$ J. H. Gerrard, "The mechanics of the vortex formation region of vortices behind bluff bodies," J. Fluid Mech. 25, 401 (1966).

${ }^{22}$ R. B. Green and J. H. Gerrard, "Vorticity measurements in the near wake of a circular cylinder at low Reynolds numbers," J. Fluid Mech. 246, 675 (1993).

${ }^{23}$ A. E. Perry, M. S. Chong, and T. T. Lim, "The vortex shedding process behind two-dimensional bluff bodies,” J. Fluid Mech. 116, 77 (1982). 